\title{
Female genital mutilation: a dilemma in child protection
}

\author{
Elspeth Webb, Bryan Hartley
}

\begin{abstract}
Demographic perspective
The city of Cardiff in South Wales saw massive expansion in the 19th century when it developed into a major port. Although the docks now see little activity Cardiff has the legacy of a highly heterogeneous population of minority ethnic groups. Among these are two groups in which the practice of female circumcision, or female genital mutilation as it is now known, is traditional: the Somalis and the Yemenis. In addition to these well established communities there are members of other ethnic groups in which it is practised.

Female genital mutilation is an ancient practice found in the main across the African Sahel extending in East Africa north into Egypt and south into Tanzania. ${ }^{1}$ It is also found in parts of the Arabian and Malay peninsulas. ${ }^{2}$ It is traditional across many different ethnic groups and faiths, including people of Nilotic, Cushitic or Bantu origin, Christians, Moslems, Jews (Falashas), and followers of indigenous religions.
\end{abstract}

\section{Forms of female genital mutilation}

There are three variations of female genital mutilation of which the most severe, infibulation, involves the cutting out of all external genitalia and sewing up of the wound leaving only a pinhole meatus for the passage of urine and menstrual fluid. This form has been described in pre-Christian Egyptian mummies. Excision and Sunna, the less radical forms of female genital mutilation, are practised by a minority in the Yemen. In Somalia it is virtually universal and takes the form of infibulation. ${ }^{13}$ It is perceived by many to be an integral part of their Islamic faith, but in fact the practice has no Koranic basis. ${ }^{2}$ A survey of obstetricians in Cardiff suggests that female genital mutilation is universal in the local Somali population and this community therefore causes most concern.

\section{Rationales for female genital mutilation} Current beliefs of the role and function of female genital mutilation are highly diverse, and include the prevention of prostitution, promotion of easier childbirth, and the prevention of the growth of male-like genital organs. ${ }^{2}$ In some areas it is believed that an infant will die if its head touches the clitoris, hence the need for excision. In others it is seen as essential to ensure female purity. In almost every group in which it is practised it is a necessary prerequisite in order for the woman to be truly female. The psychological importance of this should not be underestimated.

\section{Moral perspectives - a tension between cultures}

It is hard to imagine reasons for the development of a custom which, as well as causing great pain, can often have devastating effects on a woman's fertility, her childbearing capacity, and indeed her survival (table). Female genital mutilation, and particularly infibulation, presumably acted as an anatomical chastity belt to ensure paternity was not in doubt.

The practice of female genital mutilation is illegal in most countries, including Britain, and the majority of the countries in which it is traditional. The Prohibition of Female Circumcision Act 1985 makes it a criminal offence in this country:

'(a) to excise, infibulate or otherwise mutilate the whole or any part of the labia majora or labia minora or clitoris of another person: or (b) to aid, abet, counsel or procure the performance by another person of any of those acts on that other person's own body'.

Any person found guilty can face up to a maximum of five years' imprisonment.

As a practice which harms girls and impedes health and normal development female genital mutilation is clearly a child protection issue. In Cardiff, as elsewhere in the UK under the Children Act 1989, the Area Child Protection

Complications of female genital mutilation ${ }^{4}$

\begin{tabular}{ll}
\hline Acute & Pain \\
& Haemorrhage \\
Infection & Urethral damage \\
& Anal sphincter damage \\
Psychological trauma & Death \\
Urinary obstruction \\
Renal failure \\
Obstruction to menstrual flow \\
Haemosalpinx \\
Pyelosalpinx \\
Keloid \\
Neuroma of dorsal clitoral nerve \\
Vulval abscess \\
Dyspareunia \\
Infertility \\
Psychosexual problems \\
\hline
\end{tabular} \\ Department of Child \\ Health Unit \\ Lansdowne Hospital, \\ Cardiff CF1 8UI
}

Dr Webr. 
Committee (ACPC) has a statutory duty to protect children from harm. In the context of the cultures in which it is traditional it is perceived as a responsible act by parents ensuring their daughter a place in society. For example most Somalis in Cardiff believe that a girl who has not experienced female genital mutilation has her prospects of marriage greatly diminished. Any suggestion that the practice is harmful or abusive is highly offensive.

The Somali population of the UK has been much increased by the arrival of refugees fleeing the civil war. Around 3000 have come to South Wales. Most have experienced bereavement, fear, and great suffering before their arrival here. Many find the adjustment to a new country, and peace, difficult. Their plight is exacerbated by inadequate housing, poverty, and racism in this country. In such situations familiar customs and traditions are a vital source of security.

This tension between the desire to eradicate female genital mutilation and to enforce the law, but still to deliver services which respect peoples' race, culture and values, causes a whole series of dilemmas for workers in health, social services, and education. Some of these are particular to the newly arrived refugees, some to the whole Somali community.

We believe that a campaigning style of approach to eradicate female genital mutilation by British professionals involved in the delivery of services to the Somali community, however horrific they personally find the practice, would have negative outcomes. We are concerned, for example, that any perception by the refugee community that the main focus of our interest in the health care needs of girls and women was female genital mutilation would lead to a marked reduction in their trust, and take-up, of services, access to which is already less than good. Furthermore we do not believe such an approach would work. Banning of the practice in Africa has merely driven it underground. ${ }^{2}$ Any action that drives it underground here is likely to increase the risk faced by the children, and jeopardise any health education initiatives that we hope will contribute to the demise of the custom in the longer term.

A campaigning style could also place in jeopardy the dialogue which is currently taking place between health and social services staff and key members of the Somali community about female genital mutilation. Their message to us is simple: the eradication of female genital mutilation cannot be achieved within the context of public meetings or exposure in the media. It can only be achieved within the context of individual families. It is clear from these dialogues that there are a wide range of attitudes toward the issue within the Somali community. At one extreme are those demanding the repeal of the 1985 act, together with requests to social services to ignore referrals of female genital mutilation. At the other are people wanting to know more about the health risks and law in relation to the practice so that they can argue against it - their preference is for the professionals to provide them with that information and leave the debate to them because they know how best to handle it.

\section{A strategy for action}

We believe that female genital mutilation will only be eradicated by the communities themselves, whether resident in Africa or elsewhere. Educating the community at large both on the legal position in the UK, and the health hazards faced by the female population is ongoing. This takes the form of a leaflet available in English, Somali or Arabic, backed up by an active discussion of the issue between social service/health link workers and members of the community, and between education staff and selected school students as part of a wider health education programme on women's health. Already young Somalis locally, men and women, are questioning the need for female genital mutilation.

Any health education initiative which at best could be conceived as culturally hostile is doomed unless it occurs in the context of an overall strategy to improve the health and social welfare of the population as a whole. There are several other initiatives aimed at improving the welfare of the community. A Somali Health Forum has been established to develop response strategies specifically to meet the special needs of the refugee and host Somali populations. A catch-up surveillance programme for the child population is in progress. Schools are being approached by the local child psychiatry service to provide support to teachers coping with the behavioural problems inevitable in such a traumatised group. 'A 'well woman' clinic in the docks area has adopted an open door policy to allow newly married women a fast track referral to a female gynaecologist to perform defibulation. This is opening of the scar to allow consummation (not to be confused with disinfibulation, or reversal). Two local family doctors have set up clinics for their Somali patients. Four health advocates have been employed to support these initiatives including one male employed mainly in the mental health services. In tandem with these initiatives a subgroup of the local ACPC has developed a policy to attempt to protect girls perceived as at risk in all groups practising female genital mutilation.

It has become impossible for children to be sent to Somalia for female genital mutilation since the outbreak of the civil war there, a practice we know to have occurred in the past. It is possible to arrange for girls to be circumcised in other places, notably some of the Arab Emirates and Addis Ababa. This remains a danger. We are aware that there may be traditional circumcisors among the refugees, but have no evidence for this.

If a girl is referred to social services because she may be at risk of being mutilated the family are visited and informed clearly and firmly as to the law and the options open to the courts. After such a referral it is our experience that it is extremely difficult to gather enough evidence to proceed, within the powers available under 
the Children Act, if the girl and her parents deny that she is to undergo female genital mutilation. Can we go to court to seek care proceedings solely on comments made to a teacher in school, or on the basis of playground conversations? Should we put all Somali girls on the 'at risk' register? If they were registered how could we ensure that they have not been mutilated, given the rights parents and children have under the Children Act to refuse consent to medical examination?

Even when we have evidence that a girl has been mutilated what kind of response is appropriate? Do we want to remove a child from the care of parents who believe that they have acted in her best interests and indeed may be model parents in all other aspects of her care? In such cases we believe the best approach is to request a police investigation to see if there are grounds for prosecution of the parents and/or others under the Prohibition of Circumcision Act, rather than set in motion child protection procedures after the event.

There have been several referrals made in the last two years but in no case was there enough evidence to proceed with the powers available under the Children Act 1989. One of these referrals involved a family with three girls who subsequently were taken to Ethiopia and may have been circumcised. This case has been referred by the police to the Criminal Prosecution Service.

Naive approaches such as 'sensitive counselling in the child health clinics' are unlikely to have any impact upon a custom thousands of years old. Such an approach, involving flagging up of female genital mutilation at health consultations for unrelated issues would only alienate clients and could amount to harassment. Female genital mutilation is only discussed during client/professional contact if that contact arises out of a formal referral regarding the practice or if the presenting complaint could result from, or interact adversely with, female genital mutilation.

\section{Conclusion}

A recent editorial recommended that 'by working together local women and international organisations will be most effective in eliminating ... female genital mutilation'. ${ }^{5} \mathrm{We}$ would add that local statutory and voluntary agencies and all members of the community, not just women, should be included in any initiative. However upsetting, we are mindful that despite our best endeavours some children in this area may suffer this mutilation. We believe that our approach, that is, one based on empowerment, will in the long term be the one that protects most children and helps the communities themselves to reject the practice.

With thanks to Maria Michael and Mina McElwain (South Glamorgan Social Services), Graham Anthony (South Wales Police), Dr Heather Payne (South Glamorgan Health Authority), and John Clark.

1 Hosken F. The Hosken report-genital and sexual mutilation of females. Lexington, Mass: Women's International Network News, 1982 (revised edition).

2 Minority Rights Group. Female circumcision, excision and infibulation: the facts and proposals for change. Minority
Rights Group Report No 47. London: Minority Rights Group, 1983 (revised edition).

3 Warsame A. Social and cultural implications of infibulation in Somali. Proceedings of the International Seminar on Female Circumcision. Mogadishu: Somali Women's Democratic Organisation and Italian Association for Women in Development, 1988: 88-93.

4 Armstrong $S$. Female circumcision: fighting a cruel tradition. New Scientist 1991; 2 Feb: 42-7.

5 Ladjali M, Rattray TW, Walder RJW. Female genital mutilation. BMF 1993; 307: 460.

\section{Commentary}

Female genital mutilation has been illegal in the UK since $1985 .^{1}$ No prosecutions have been brought in the UK (Guardian 22 Nov 93) but in November of 1993 a medical practitioner was brought before the General Medical Council charged with performing multiple female circumcisions, knowing the operation to be against the law. He was struck off.

It is estimated that in the UK 10000 girls are currently at risk of genital mutilation, a traditional practice that is not based in religion but rather concepts of fertility, female sexuality, and marriageability. ${ }^{2}$ Genital mutilation is widely practised by many ethnic groups from west, east, and north eastern parts of Africa. Hosken provided an estimate of the prevalence of genital mutilation from over $90 \%$ in Somalia to $50 \%$ in Egypt to $20 \%$ in Ghana. ${ }^{3}$ Over half the African nations do not practise female genital mutilation. ${ }^{4}$ The African Charter on the Rights and Welfare of the Child stresses that positive traditional values and cultures be preserved and strengthened, but requests in its Article 21, that, 'appropriate measures be taken in order to eradicate traditional practices and customs which are prejudicial to the health of the child'. Currently 26 African countries have committees established after an initiative in 1984 to work towards eliminating female genital mutilation and other damaging customs (the Inter-African Committee Against Harmful Traditional Practices Affecting Women and Children).

The current debate extends from the United Nations, the Convention on the Rights of the Child advocates eradication of genital mutilation, to governments, but most important is the impact of women working at a local level.

The description of female mutilation and the possible physical and psychological sequelae are well known for the girl or woman ${ }^{5}$ but less well documented is the effect upon her partner and the consequences for their sexual relationship.

The way forward is difficult but much has already been achieved. There is legislation available in the UK, the 1985 Act, the Children Act $1989,{ }^{6}$ and there is advice in Working Together 1991 as to how children might be protected. ${ }^{7}$ However, it is 'through sensitive community education and social work intervention' that progress is likely to be made. ${ }^{4}$ As a last resort a prohibitive steps order or a care order may be needed to ensure the girl's protection (Children Act 1989).

From the 1989 First National Conference on Female Genital Mutilation in the UK guidelines as to management were agreed ${ }^{8}$ :

- Female genital mutilation is the preferred terminology 